\title{
The solid-state photo-CIDNP effect
}

\author{
Jörg Matysik · Anna Diller · Esha Roy • \\ A. Alia
}

Received: 23 June 2008/Accepted: 12 January 2009/Published online: 24 February 2009

(C) The Author(s) 2009. This article is published with open access at Springerlink.com

\begin{abstract}
The solid-state photo-CIDNP effect is the occurrence of a non-Boltzmann nuclear spin polarization in rigid samples upon illumination. For solid-state NMR, which can detect this enhanced nuclear polarization as a strong modification of signal intensity, the effect allows for new classes of experiments. Currently, the photo- and spinchemical machinery of various RCs is studied by photoCIDNP MAS NMR in detail. Until now, the effect has only been observed at high magnetic fields with ${ }^{13} \mathrm{C}$ and ${ }^{15} \mathrm{~N}$ MAS NMR and in natural photosynthetic RC preparations in which blocking of the acceptor leads to cyclic electron transfer. In terms of irreversible thermodynamics, the highorder spin structure of the initial radical pair can be considered as a transient order phenomenon emerging under non-equilibrium conditions and as a first manifestation of order in the photosynthetic process. The solid-state photoCIDNP effect appears to be an intrinsic property of natural RCs. The conditions of its occurrence seem to be conserved in evolution. The effect may be based on the same fundamental principles as the highly optimized electron transfer. Hence, the effect may allow for guiding artificial photosynthesis.
\end{abstract}

Keywords Electron transfer - Spin polarization . Radical pair · Bacterial RC · Solid-state NMR

$\begin{array}{ll}\begin{array}{ll}\text { Abbreviations } \\ \text { CIDNP }\end{array} & \begin{array}{l}\text { Chemically induced dynamic nuclear } \\ \text { polarization }\end{array} \\ \text { CSA } & \text { Chemical shift anisotropy }\end{array}$

J. Matysik $(\bowtie) \cdot$ A. Diller · E. Roy · A. Alia

Leiden Institute of Chemistry, Leiden University, Einsteinweg 55,

P.O. Box 9502, 2300 RA Leiden, The Netherlands

e-mail: j.matysik@chem.leidenuniv.nl

$\begin{array}{ll}\text { DD } & \text { Differential decay } \\ \text { ENDOR } & \text { Electron nuclear double resonance } \\ \text { EPR } & \text { Electron paramagnetic resonance } \\ \text { Hf } & \text { Hyperfine } \\ \text { HOMO } & \text { Highest occupied molecular orbital } \\ \text { ISC } & \text { Inter-system crossing } \\ \text { MAS } & \text { Magic angle spinning } \\ \text { MFE } & \text { Magnetic field effect } \\ \text { photo-CIDEP } & \text { Photochemically induced dynamic } \\ & \text { electron polarization } \\ \text { photo-CIDNP } & \text { Photochemically induced dynamic nuclear } \\ & \text { polarization } \\ \text { PSI, II } & \text { Photosystems I, II } \\ R b . & \text { Rhodobacter } \\ \text { RPM } & \text { Radical pair mechanism } \\ \text { S } & \text { Singlet } \\ \text { T } & \text { Triplet } \\ \text { TSM } & \text { Three-spin mixing }\end{array}$

\section{Photo-CIDNP MAS NMR as spectroscopic method}

Due to small Zeeman splitting and resulting unfavorable Boltzmann distribution, all magnetic resonance methods are intrinsically low in sensitivity. The solid-state photoCIDNP effect has been shown to be a method to overcome this limitation for magic-angle spinning (MAS) NMR by photochemical production of non-Boltzmann nuclear spin states and to allow for detailed studies of the photochemical machineries of RCs (Zysmilich and McDermott 1994; for reviews: Jeschke and Matysik 2003; Daviso et al. 2008a). Signal enhancement of a factor of about 10,000 for ${ }^{13} \mathrm{C}$ NMR (Fig. 1) has been observed in several RCs (Prakash et al. 2005a, 2006; Roy et al. 2006). The corresponding ratio of the nuclear spin populations of $p_{\beta} / p_{\alpha}=1.2329$ could be expressed in terms of a spin 


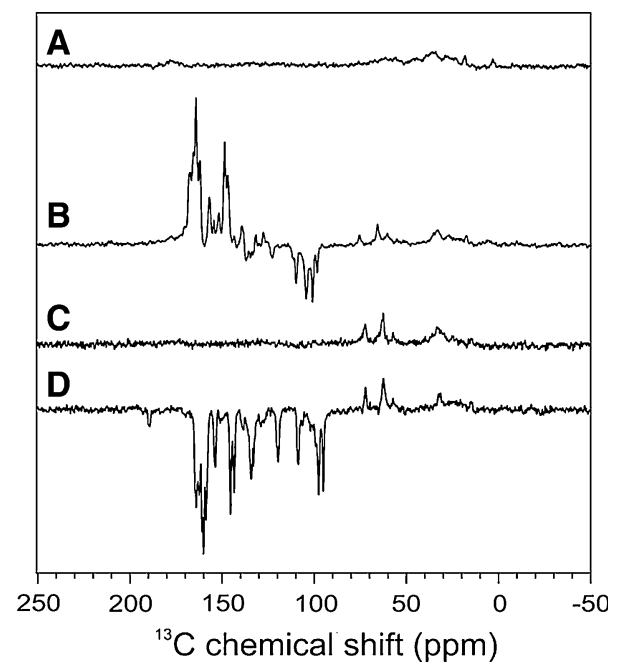

Fig. $1{ }^{13} \mathrm{C}$ MAS NMR spectra of isolated RCs of Rb. sphaeroides R26 (A, B) and WT (C, D) in the dark (A, C) and under illumination with continuous white light. All spectra were obtained at 4.7 Tesla (200 MHz proton frequency) with a cycle delay of 4 seconds at a temperature of $230 \mathrm{~K}$ (Prakash et al. 2005a, b, 2006)

temperature of $T_{\mathrm{S}}=-0.01146 \mathrm{~K}$. Although temperatures are defined for equilibrium state only, this number may provide an impression about the high degree of spin order obtained. Until now, photo-CIDNP MAS NMR has been measured at fields between 4.7 and 17.6 Tesla, and the enhancement factor is usually the highest at lowest field (Prakash et al. 2005a, 2006; Roy et al. 2006, 2008). Full control over the parameters governing the generation of nuclear polarization may allow for enhancement by a factor of 100,000 (Jeschke and Matysik 2003). The strong signal enhancement allows for direct observation of the photochemical machinery of RCs in membranes (Roy et al. 2008) or cells (Prakash et al. 2006). Furthermore, the solidstate photo-CIDNP effect also provides new channels for signal recovery allowing to increase the cycle delay and to shorten the measuring time (Diller et al. 2007a).

The strong increase of NMR signal intensity and selectivity allows for detailed analysis of the electronic structure of the active cofactors. The NMR chemical shifts are related to the electronic structure of the electronic ground state after the photocycle, and the photo-CIDNP intensities are related to local electron spin densities. Hence, photo-CIDNP MAS NMR allows for investigation of both, the electronic ground state and the radical pair state. This method has shown that the special pair of RCs of Rhodobacter (Rb.) sphaeroides wildtype (WT) is already asymmetric in its electronic ground state (Schulten et al. 2002), although the origin of the asymmetry is not yet understood. In the radical cation state, the ratio between the two moieties has been determined to be around 3:2 (Prakash et al. 2005a), which is in good agreement with ${ }^{1} \mathrm{H}$ ENDOR data (Lendzian et al. 1993). Time-resolved
photo-CIDNP MAS NMR experiments allowed for determination of the electron spin density distribution of the radical pair at the atomic resolution and precise kinetic modeling (Daviso et al. 2008b). On the other hand, the donors of the RCs of the green sulfur bacteria Chlorobium tepidum (Roy et al. 2007) and of the Heliobacterium mobilis (Roy et al. 2008) have been shown to be monomeric or highly symmetric. The donor of photosystem II (PS2) has been shown to have a highly asymmetric electron spin distribution (Matysik et al. 2000a) which has been proposed to be caused by involvement of an axial histidine (Diller et al. 2007b). In contrast, the cofactors in the donor of photosystem I (PSI) are undisturbed (Alia et al. 2004).

\section{Occurrence and origin of the solid-state photo-CIDNP effect}

Photochemical induced dynamic nuclear polarization (photo-CIDNP) is a well-known phenomenon in liquid NMR (for reviews: Hore and Broadhurst 1993; Roth 1996; Goez 1997). In this article, the term "polarization" is exclusively used for spin polarization, i.e., the difference in population of $\alpha$ and $\beta$ nuclear or electron spins. Chemical induced dynamic nuclear polarization (CIDNP) has first been reported to occur in dark organic radical reactions in 1967 (Bargon and Fischer 1967; Bargon et al. 1967; Ward and Lawler 1967). Soon, CIDNP has been also observed in a photochemical reaction (Cocivera 1968). The term "photochemical induced dynamic nuclear polarization (photo-CIDNP)" refers to this specific photochemical origin of the phenomenon. CIDNP has been explained by the radical pair mechanism (RPM) (Closs and Closs 1969; Kaptein and Oosterhoff 1969). This mechanism is caused by different nuclear spin sorting leading to different chemical fates of the products. Due to coherent $S-T_{0}$ mixing, upon inter-system crossing (ISC) the spin state of the radical pair is oscillating between a singlet- and a triplet-state. The radicals forming a singlet-radical pair may recombine, while the triplet products are forced to diffuse apart. Hence, this mechanism requires mobility and can build-up CIDNP only in the fluid phase. Later, the mechanism has been extended to $S-T_{+}$and $S-T_{-}$mixing as well, for example occurring in biradicals and at low fields (Closs and Doubleday 1972; de Kanter et al. 1977). In addition, also an electron-nuclear Overhauser cross-relaxation mechanism operating in liquid state has been observed, (Adrian 1974; Closs 1975) which also explains polarization buildup in cyclic reactions (Closs et al. 1985). In a triplet Overhauser mechanism (Adrian 1977) nuclear polarization is created upon ISC from an excited singlet- to a triplet-state. While the RPM is based on fast coherent evolution of an electron-electron-nuclear spin 
system and spin state sorting in alternative reaction pathways, the Overhauser mechanism relies on usually slower incoherent cross relaxation that transfers polarization from electrons to nuclei. The latter mechanism requires a matching of the cross-relaxation time to the life time of the radical pair, while transient polarization from the RPM cancels under steady-state conditions for cyclic reactions.

In the same time, two other spin-chemical phenomena were discovered in photosynthetic systems: (i) photochemically induced dynamic electron polarization (photo-CIDEP), which is enhancement of EPR signals upon illumination, has been observed in chloroplasts (Blankenship et al. 1975) and RCs of purple bacteria (Hoff et al. 1977a) (ii) the magnetic field effect (MFE) on the triplet yield was discovered in bacterial RCs (Blankenship et al. 1977; Hoff et al. 1977b). Although the exact mechanism was not understood, both phenomena were interpreted in terms of magnetic-field dependent interactions of electrons with nuclei (Hoff et al. 1977b; Werner et al. 1978; for review: Hoff 1984). Based on this assessment, "new classes of experiments" were predicted for NMR (Goldstein and Boxer 1987). In 1994, Zysmilich and McDermott observed for the first time this new type of photo-CIDNP in frozen and quinone-blocked RCs of purple bacteria of $R b$. sphaeroides R26 (Zysmilich and McDermott 1994). Meanwhile, the exact spin-chemical mechanism is much better understood (Jeschke and Matysik 2003; Daviso et al. 2008a). In particular, experiments on the magnetic field dependence (Prakash et al. 2005a, 2006), with different NMR cycle delays (Diller et al. 2007a) and with time-resolution using flash laser (Daviso et al. 2008b) allowed for deeper insight. In these studies, it has been demonstrated that up to three mechanisms are involved to build up photo-CIDNP under continuous illumination, which may run in parallel. In all mechanisms the break of the balance of the opposite nuclear spin populations in the two decay branches of the radical pair states (Fig. 2) leads to net steady-state nuclear polarization, which is detected in the NMR experiment. In time-resolved photo-CIDNP MAS NMR experiments, transient nuclear polarization, due to the different kinetics on the two decay channels of the radical pair (see below), may occur additionally (Daviso et al. 2008b). This phenomenon, however, will not be discussed further in the present review.

Initially, the spin-correlated radical pair is formed in a pure singlet state and it is, therefore, highly electron polarized (Fig. 2). This electron polarization can be observed by EPR as photo-CIDEP. There are two transfer mechanisms which transfer this electron polarization to nuclear polarization:

(i) Electron-electron-nuclear three-spin mixing (TSM) breaks the balance of the two radical pair decay channels by spin evolution within the correlated

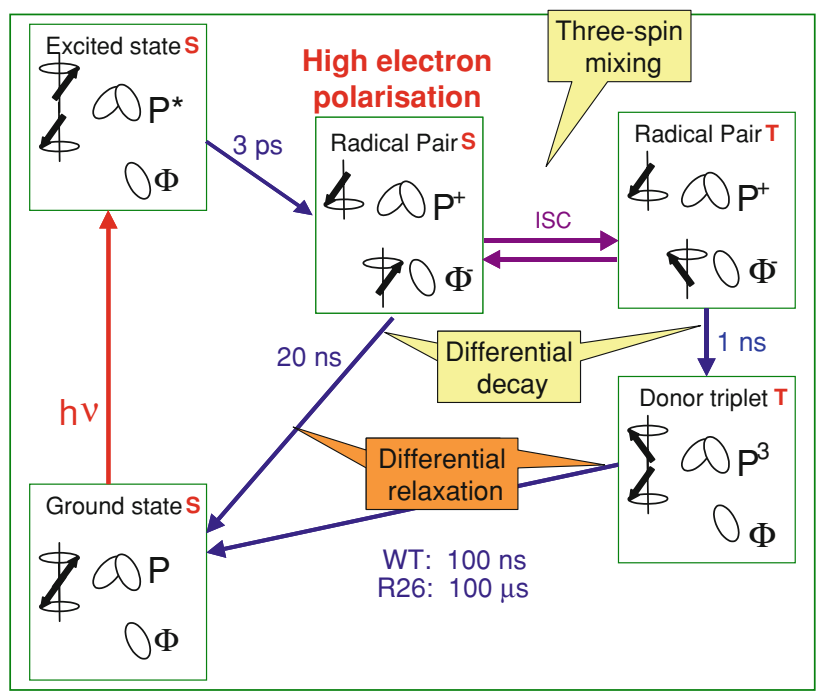

Fig. 2 The mechanisms of photo-CIDNP production in natural RCs of Rb. sphaeroides WT and R26 as established for high-field conditions. From the photochemically excited donor, $\mathrm{P}^{*}$, an electron is transferred to the primary acceptor $\Phi$, a bacteriopheophytin. The radical pair $\left(\mathrm{P}^{+\bullet} \Phi^{-\bullet}\right)$ is initially in a pure singlet state and highly electron polarized. Due to hyperfine interaction, the radical pair is oscillating between a singlet and a $\mathrm{T}_{0}$ triplet state. During intersystem crossing (ISC), electron polarization is transferred to nuclei by threespin mixing (TSM). Back-ET from the singlet state of the radical pair leads to the electronic ground-state. Back-ET from the triplet state of the radical pair leads to the donor triplet $\left({ }^{3} \mathrm{P}\right)$ state. In the differential decay (DD) mechanism, net photo-CIDNP is produced by different contributions of the two spin states of the spin-correlated radical pair to the spin evolution. In RCs having a long lifetime of the donor triplet, ${ }^{3} \mathrm{P}$, as in $\mathrm{R} 26$, the differential relaxation (DR) mechanism occurs since nuclear spin relaxation is significant on the triplet branch, causing incomplete cancellation of nuclear polarization of both branches

radical pair state depending on the signs of the electron-electron and of the electron-nuclear interactions (Jeschke 1997, 1998). This process occurs during ISC in solids. In contrast to Overhauser cross relaxation, it is a coherent process that relies on anisotropy of the hyperfine (hf) coupling. The mechanism requires fulfillment of the triple-matching condition $2|\Delta \Omega|=$ $2\left|\omega_{\mathrm{I}}\right|=|A|$, which means that the difference of the electron Zeeman frequencies $\Delta \Omega$ must match the nuclear Zeeman frequency $\omega_{\mathrm{I}}$, and that both together must match to the secular (diagonal) part of the hf interaction. This corresponds to a matching of three energy levels enabling the flow of polarization from an electron spin pair to a nucleus. This transfer is driven by the pseudosecular (off-diagonal) part $\mathrm{B}$ of the hf interaction. As this pseudosecular part vanishes when hf anisotropy is averaged, the TSM mechanism is absent in the liquid state.

(ii) In the differential decay (DD) mechanism, (Polenova and McDermott 1999) the symmetry between the two 
decay channels is broken by the different lifetimes of the states of the correlated radical pair. This means that in the two radical pair spin states different fractions of polarization flow from the electrons to the nuclei. The result is an additional imbalance between the fractions of nuclei in spin-up and spin-down states in the two decay channels. In this case, the energetic matching condition is just $2\left|\omega_{\mathrm{I}}\right|=|A|$. Again an anisotropic hf coupling is required, so that the DD mechanism is also absent in the liquid state. In this mechanism both coherent spin-state mixing and incoherent radical pair decay contribute to polarization transfer. The efficiency of this mechanism depends on the ratio of both lifetimes. It is remarkable that nature has chosen a ratio which maximizes this effect (Fig. 3) (Jeschke and Matysik 2003).

In addition to the two polarization transfer mechanisms TSM and DD, in samples having a long lifetime of the triplet donor $\left({ }^{3} \mathrm{P}\right)$, a third mechanism may occur that creates nuclear polarization:

(iii) In the differential relaxation (DR) mechanism the breaking of antisymmetry of the polarization in the singlet and triplet branch occurs in a non-coherent way. The enhanced relaxation of nuclear spins in the proximity of the high-spin donor partially cancels the nuclear polarization in the donor cofactor. Hence, when the ${ }^{3} \mathrm{P}$ lifetime is comparable to or exceeds the paramagnetically enhanced longitudinal relaxation time, net polarization occurs due to partial extinction of nuclear polarization of the triplet state of the

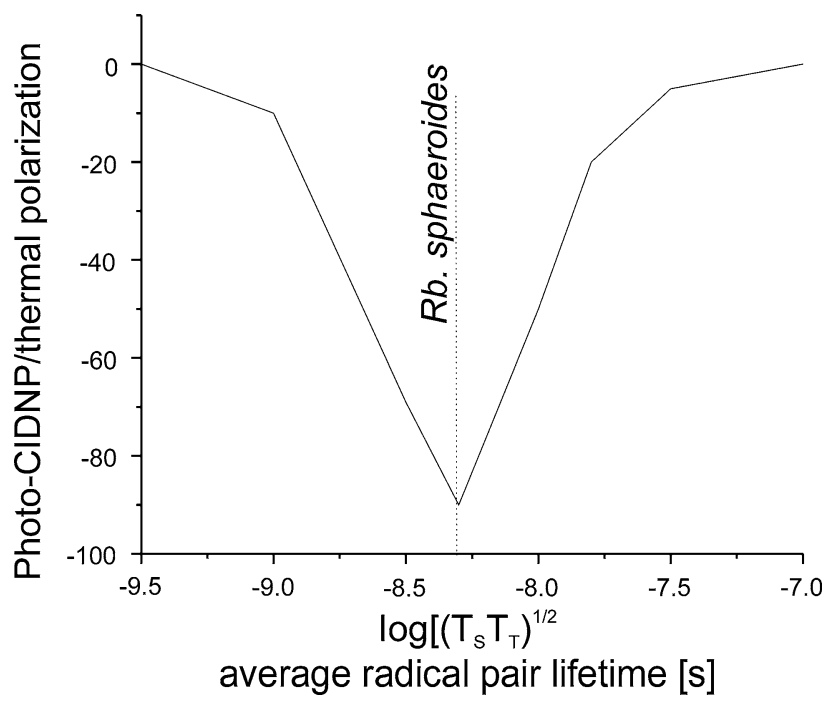

Fig. 3 Dependence of the DD mechanism of the solid-state photoCIDNP effect on the lifetime of the radical pair. The value found for $\mathrm{RCs}$ of $R b$. sphaeroides coincides with the maximum effect. $\mathrm{T}_{\mathrm{S}}$ and $\mathrm{T}_{\mathrm{T}}$ are the lifetimes of the singlet and the triplet state of the radical pair, respectively radical pair (Goldstein and Boxer 1987; McDermott et al. 1998). This extinction of polarization also leads to a significantly enhanced recovery rate of the polarization in steady-state experiments (Diller et al. 2007a).

TSM and DD are coherent mechanisms transferring polarization from electrons to nuclei, while the DR creates nuclear net polarization by partial extinction of the polarization of a selected sort of nuclear spins. In RCs of $R b$. sphaeroides WT at high magnetic fields, the TSM leads to an excess of $\beta$ nuclear spins in the branch of the triplet radical pair decay, and the DD causes an excess of $\alpha$ nuclear spins in the branch of the singlet radical pair decay. The TSM, however, is larger than the DD contribution, and due to the total majority of $\beta$ spins all signals turn negative (emissive) (Prakash et al. 2005a). In RCs of Rb. sphaeroides R26, in which the absence of the carotenoid causes a ${ }^{3} \mathrm{P}$ lifetime of $\sim 100 \mu \mathrm{s}$, the DR appears to occur in addition to the TSM and DD. The DR adds more $\alpha$ than $\beta$ nuclear spins to the net spin balance of the donor carbons, turning selectively the donor signals enhanced absorptive (positive) (Prakash et al. 2006). In any case, these transient spin structures are highly ordered, or, to put it in the terminology of thermodynamics, are low in spin entropy.

\section{Irreversible thermodynamics and the solid-state photo-CIDNP effect}

Photosynthesis itself can be considered as one of these processes of emerging order, as it has already been anticipated by Boltzmann in 1886:

Der allgemeine Lebenskampf der Lebewesen ist daher nicht ein Kampf um die Grundstoffe_-die Grundstoffe aller Organismen sind in Luft, Wasser und Erdboden im Überfluß vorhanden - auch nicht um Energie, welche in Form von Wärme, leider unverwandelbar, in jedem Körper reichlich vorhanden ist, sondern ein Kampf um die Entropie, welche durch den Übergang der Energie von der heißen Sonne zur kalten Erde disponibel wird. Diesen Übergang möglichst auszunutzen, breiten die Pflanzen die unermeßlichen Flächen ihrer Blätter aus und zwingen die Sonnenenergie in noch unerforschter Weise, ehe sie auf das Temperaturniveau der Erdoberfläche herabsinkt, chemische Synthesen auszuführen, von denen man in unseren Laboratorien noch keine Ahnung hat. Die Produkte dieser chemischen Küche bilden das Kampfobjekt für die Tierwelt. (Boltzmann 1886):

[The general struggle of all life forms is therefore not a struggle for the elements-the elements air, water, and earth are available in excess. It is also not a struggle for energy, which in the form of heat, unfortunately 
non-transformable, is amply available in each organism. It is rather a struggle for entropy, which becomes available through the transition of energy from the hot sun to the cold earth. In order to make use of this transition, plants open the huge surfaces of their leaves and force the sun's energy, before it cools down to the temperature of the earth, to carry out chemical reactions in a still unknown way of which we in our laboratories have no idea. The products of this chemical kitchen are what the animal world seeks to attain (Translation by Johannes Blum-Seebach, Gießen)].

The surface of the earth can be approximated as a closed system, over which a continuous flow of solar radiative energy pours and dissipates into the cold universe. As described by irreversible thermodynamics, under such conditions of high energy throughput and entropy production, ordered structures may emerge. Negentropy (i.e., order) is created locally in a system which is surrounded by an ocean of dissipative entropy production. Examples are found in the world of dead matter as well as in the biosphere (for reviews see Kondepudi and Prigogine 1998; Haken 2004). Life, being stable far from equilibrium, as already pointed out by Schrödinger (1944), can be understood in terms of dissipative structures as well. Doubtless, photosynthesis plays a key role for the occurrence of living order on earth. As proposed by Boltzmann, it is the negentropy stored in the photosynthetic products which maintain the structures of life.

The photosynthetic membrane appears to be the location at which the high and dissipative energy through-put occurs, and in which negentropy is created for terrestrial life. The radical pair formation is the first step of the process of order formation. The separation of charges as well as the organization of the electron spins lead to a transient high-order (i.e., low-entropy) state. Hence, photoCIDEP can be considered as the first product of photosynthetic production of order. The solid-state photo-CIDNP effect might be considered as part of this initial process of photosynthetic construction of order. Since the energies involved are marginally compared to the reaction energies, only kinetic effects of the spin-chemistry on the reaction yield could be considered. In fact, various magnetic-field effects on plant growth have been observed experimentally (For reviews, see Belyavskaya 2004; Galland and Pazur 2005).

On the other hand, one may argue that the solid-state photo-CIDNP effect as observed till now does not occur under natural conditions but requires high magnetic fields and cyclic electron transfer, which is reached, for example in RCs of $R b$. sphaeroides by reduction or removal of the quinones. Therefore, one may consider the solid-state photo-CIDNP effect as a by-process, occurring under artificial conditions, which is accidentally a very useful as an analytical tool for the electronic structure of the photochemical machinery of RCs. In any case, due to its limited size and complexity as well as due to its relevance, the order and dissipation processes of spins during the radical pair formation in photosynthetic RCs provide a stimulating target for irreversible thermodynamics of microscopic processes.

\section{Intrinsic property of $\mathrm{RCs}$}

The list of RCs showing the solid-state photo-CIDNP effect is growing (Table 1). The list contains systems from various bacteria as well as from plants. In all natural RCs, in which we were able to induce cyclic ET, we observed the solidstate photo-CIDNP effect as well. It appears that the occurrence of the solid-state photo-CIDNP effect is an intrinsic property of photosynthetic RCs (Roy et al. 2008). Despite various concepts of evolution of photosynthetic organisms compete in the literature, it is safe to say that the bacterial systems showing photo-CIDNP, green sulfur bacteria, purple non-sulfur bacteria and heliobacteria, originate from very different branches of the evolutionary tree (Fig. 4). The window of occurrence (see e.g., Fig. 3) of this effect is rather limited by kinetic and magnetic parameters (Jeschke and Matysik 2003; Daviso et al. 2008a), however, it appears that the evolution remains confined on a small area of the infinite parameter landscape. Although a lucky coincidence cannot be ruled out, it appears that the solid-state photo-CIDNP effect is highly conserved in the evolution of photosynthetic organisms. Despite many efforts, in no artificial RC system, having generally low-quantum yield, the solid-state photo-CIDNP effect has been observed yet. Therefore, there seems to be a link between the conditions of occurrence of photo-CIDNP in RCs and the conditions of the unsurpassed efficient light-induced electron transfer in RCs. Such link also could allow using the strength of the solidstate photo-CIDNP effect as a heuristic guide to improve the functional properties of artificial RCs.

\section{Solid-state photo-CIDNP effect and efficient electron transfer}

The question occurs on the character of the assumed link between the solid-state photo-CIDNP effect and efficient electron transfer. The phenomenon of the solid-state photoCIDNP effect is akin to a non-equilibrium phenomenon known in EPR which is called "observer spin". In a spin triad formed by a spin-correlated radical pair, for example, a radical cation-radical anion pair $\left[\mathrm{D}^{+\bullet} \mathrm{A}^{-\bullet}\right]$ and the observer spin $\mathrm{R}^{\bullet}$, the observer spin may act as an electron spin catalyst facilitating the radical pair reaction (for review see Ivanov 2005). The observer spin may acquire 
Table 1 Systems in which the solid-state photo-CIDNP effect has been observed

\begin{tabular}{|c|c|c|}
\hline \multirow[t]{2}{*}{ Species } & \multicolumn{2}{|l|}{ Reference } \\
\hline & ${ }^{13} \mathrm{C}$ & ${ }^{15} \mathrm{~N}$ \\
\hline \multicolumn{3}{|l|}{ Plants } \\
\hline Spinacia oleracea (Spinach): PS1 & Alia et al. (2004) & Diller et al. (2007b) \\
\hline Spinacia oleracea (Spinach): PS2 & $\begin{array}{l}\text { Matysik et al. (2000a) } \\
\text { Diller et al. (2005) }\end{array}$ & Diller et al. (2007b) \\
\hline \multicolumn{3}{|l|}{ Purple bacteria } \\
\hline Rhodobacter sphaeroides WT & $\begin{array}{l}\text { Schulten et al. (2002) } \\
\text { Prakash et al. (2005a) }\end{array}$ & Daviso et al. (2008c) \\
\hline Rhodobacter sphaeroides R26 & $\begin{array}{l}\text { Zysmilich and } \\
\text { McDermott (1996a) } \\
\text { Matysik et al. (2000b) } \\
\text { Prakash et al. (2006) }\end{array}$ & $\begin{array}{l}\text { Zysmilich and } \\
\text { McDermott (1994, (1996b) } \\
\text { Prakash et al. (2005b) } \\
\text { Daviso et al. (2008c) }\end{array}$ \\
\hline Rhodopseudomonas acidophila & Diller et al. (2008) & \\
\hline \multicolumn{3}{|l|}{ Gram positive bacteria } \\
\hline Heliobactrium mobilis & Roy et al. (2008) & \\
\hline \multicolumn{3}{|l|}{ Green sulfur bacteria } \\
\hline Chlorobium tepidum & Roy et al. (2007) & \\
\hline
\end{tabular}

Fig. 4 Phylogenetic tree based on the small subunit RNA method. Groups containing (B)Chl-based photosynthetic organisms are encircled (from: Blankenship 2002). The solidstate photo-CIDNP effect has been observed in purple bacteria, green sulfur bacteria, gram positives and plants. Heliobacteria belong to the gram positive organisms

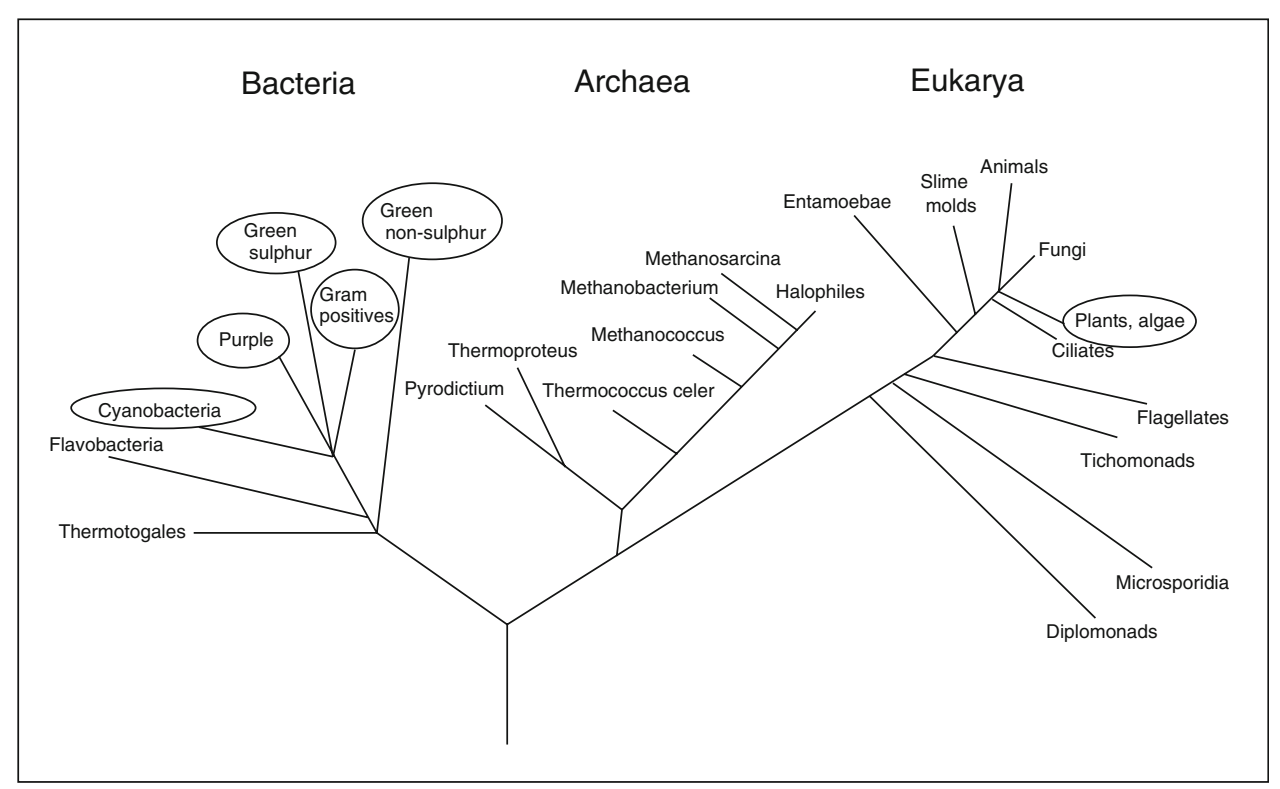

significant non-Boltzmann electron polarization, and this CIDEP has been taken as an indication of its catalytic activity. For example, in the primary radical pair of bacterial RCs, the pre-reduced first quinone acceptor $\mathrm{Q}_{\mathrm{A}}{ }^{-\bullet}$ obtains significant CIDEP (Gast and Hoff 1979; Gast et al. 1983; de Groot et al. 1985). For the ET from $Q_{A}$ to $Q_{B} a$ spin-catalytic role of the non-heme iron to facilitate spinselective ET has been proposed (Ivanov et al. 1999). In this concept ISC accelerated by the spin-catalytic active nonheme iron promotes the indirect ET from the triplet radical pair ${ }^{3}\left[\mathrm{Q}_{\mathrm{A}}{ }^{-} \mathrm{Q}_{\mathrm{B}}{ }^{-}\right]$and therefore the product formation to ${ }^{1}\left[\mathrm{Q}_{\mathrm{A}} \mathrm{Q}_{\mathrm{B}}{ }^{2-}\right]$. One may assume that the phenomenon of the solid-state photo-CIDNP effect could be rationalized in terms of nuclear observer spins, on the one hand obtaining nuclear polarization, on the other hand providing a spincatalyst for ET. Under natural conditions, however, the primary radical pair lives $200 \mathrm{ps}$, by far too short to allow for hf interaction. Hence, the effect cannot be the cause of the efficiency, but the assumed correlation between the parallel occurrence of effect and high efficiency may be based on common principles. There may be some until now unknown fundamental principles of photosynthetic charge separation and stabilization that leading to both phenomena. In that case, photo-CIDNP MAS NMR would be 
useful for studies in artificial photosynthesis for three reasons: (i) as an analytical tool, (ii) as heuristic guide based on the strength of the effect, and (iii) by the possibility for exploration of the fundamental principles.

These fundamental principles may be related to highly optimized constraints in geometry and ET kinetics as chosen and conserved by nature. It has been pointed out that both the solid-state photo-CIDNP effect and the efficient light-induced ET require optimized overlap of the wavefunctions (Jeschke and Matysik 2003) corresponding to moderate electron-electron coupling parameters. A clear picture of the required architecture of orbitals, however, is still missing. Such concept of overlapping static orbitals of the cofactors would be sufficient for the microscopic description of both the ET and the coherent origin of the solid-state photo-CIDNP effect. On the other hand, understanding of both processes on the protein level would allow for including the dynamic role of energy dissipation and entropy production in the transfer of electrons and polarization. It is possible that both ET and the solid-state photo-CIDNP effect require optimized dissipation channels. The relevance of protein relaxation for photosynthetic ET has been stressed (Cherepanov et al. 2001). Under conditions of irreversible thermodynamics, self-organized ET, in which improved entropy management allows for active coupling of the ET to a matrix with non-linear response, may lead to negative friction and gating (Tributsch and Pohlmann 1998; Tributsch 2006). Hence, experiments mapping light-induced changes at the atomic resolution may provide the empirical basis for the determination of the origin of the parallel transfer of electrons and of electron polarization to nuclei.

\section{Summary and outlook}

The solid-state photo-CIDNP effect is a non-Boltzmann spin state which could be described as order phenomenon by irreversible thermodynamics. ${ }^{13} \mathrm{C}$ and ${ }^{15} \mathrm{~N}$ photo-CIDNP MAS NMR has been demonstrated to be a valuable analytical tool for the functional analysis of the primary photochemical machinery of RCs, although several possible applications have not yet been explored. It appears that the solid-state photo-CIDNP effect is an intrinsic property of natural RCs and correlated to efficient ET. The spinchemical mechanisms causing the solid-state photo-CIDNP effect are understood, but it still has to be explored why nature has chosen and conserved a set of electronic and kinetic parameters leading to both, efficient ET and the solid-state photo-CIDNP effect.

Acknowledgments The authors thank E. Daviso, G. Jeschke, T. Rohmer, K·B. Sai Sankar Gupta, G.J. Janssen and S. Thamarath-
Surendran for stimulating discussions. This project has been supported by a grant of the Volkswagen-Stiftung (I/78010, Förderinitiative Elektrontransfer) and by an NWO Vidi grant (700 53 423) to J.M.

Open Access This article is distributed under the terms of the Creative Commons Attribution Noncommercial License which permits any noncommercial use, distribution, and reproduction in any medium, provided the original author(s) and source are credited.

\section{References}

Adrian FJ (1974) A possible Overhauser mechanism for ${ }^{19} \mathrm{~F}$ nuclear spin polarization in the reaction of fluorobenzyl halides with sodium naphthalene. Chem Phys Lett 26:437-439. doi:10.1016/ 0009-2614(74)89067-6

Adrian FJ (1977) Triplet Overhauser mechanism of CIDNP. In: Muus LT et al (eds) Chemically induced magnetic polarization. D. Reidel Publishing Company, Dordrecht, pp 369-381

Alia A, Roy E, Gast P et al (2004) Photochemically induced dynamic nuclear polarization in photosystem I of plants observed by C-13 magic-angle spinning NMR. J Am Chem Soc 126:12819-12826. doi:10.1021/ja048051+

Bargon J, Fischer H (1967) Kernresonanz-Emissionslinien während rascher Radikalreaktionen. 2. Chemisch induzierte dynamische Kernpolarisation. Z Naturforsch A 22:1556-1562

Bargon J, Fischer H, Johnson U (1967) Kernresonanz-Emissionslinien während rascher Radikalreaktionen. I. Aufnahmeverfahren und Beispiele. Z Naturforsch A 22:1551-1555

Belyavskaya NA (2004) Biological effects due to weak magnetic fields on plants. Adv Space Res 34:1566-1574. doi:10.1016/j.asr. 2004.01.021

Blankenship RE (2002) Molecular mechanisms of photosynthesis. Blackwell Science, Oxford

Blankenship RE, McGuire A, Sauer K (1975) Chemically induced dynamic electron polarization in chloroplasts at room temperature: evidence for triplet state participation in photosynthesis. Proc Natl Acad Sci USA 72:4943-4947. doi:10.1073/pnas.72. 12.4943

Blankenship RE, Schaafsma TJ, Parson WW (1977) Magnetic-field effects on radical pair intermediates in bacterial photosynthesis. Biochim Biophys Acta 461:297-305. doi:10.1016/0005-2728(77) 90179-7

Boltzmann L (1905) Der zweite Hauptsatz der mechanischen Wärmetheorie (Vortrag, gehalten in der feierlichen Sitzung der Kaiserlichen Akademie der Wissenschaften am 29. Mai 1886.) In: Populäre Schriften. Barth Verlag, Leipzig

Cherepanov DA, Krishtalik LI, Mulkidjanian AY (2001) Photosynthetic electron transfer controlled by protein relaxation: analysis by Langevin stochastic approach. Biophys J 80:1033-1049. doi: 10.1016/S0006-3495(01)76084-5

Closs GL (1975) On the Overhauser mechanism of chemically induced nuclear polarization as suggested by Adrian. Chem Phys Lett 32:277-278

Closs GL, Closs LE (1969) Induced dynamic nuclear spin polarization in reactions of photochemically and thermally generated triplet diphenylmethylene. J Am Chem Soc 91:4549-4550. doi: 10.1021/ja01044a041

Closs GL, Doubleday CE (1972) Chemically induced dynamic nuclear spin polarization derived from biradicals generated by photochemical cleavage of cyclic ketones, and the observation of a solvent effect on signal intensities. J Am Chem Soc 94:92489249. doi:10.1021/ja00781a056

Closs GL, Miller RJ, Redwine OD (1985) Time-resolved CIDNP: applications to radical and biradical chemistry. Acc Chem Res 18:196-202. doi:10.1021/ar00115a001 
Cocivera M (1968) Optically induced Overhauser effect in solution. Nuclear magnetic resonance emission. J Am Chem Soc 90:3261-3263. doi:10.1021/ja01014a064

Daviso E, Jeschke G, Matysik J (2008a) Photochemically induced dynamic nuclear polarization (Photo-CIDNP) magic-angle spinning NMR. In: Aartsma TJ, Matysik J (eds) Biophysical techniques in photosynthesis II. Springer, Dordrecht

Daviso E, Diller A, Alia A et al (2008b) Photo-CIDNP MAS NMR beyond the $T_{1}$ limit by fast cycles of polarization extinction and polarization generation. J Magn Reson 190:170-178. doi: 10.1016/j.jmr.2007.10.001

Daviso E, Sai Sankar Gupta KB, Prakash S et al (2008c) ${ }^{15} \mathrm{~N}$ photoCIDNP MAS NMR on RCs of Rhodobacter sphaeroides WT and R26. In: Allen J, Gantt E, Golbeck J, Osmond B (eds) Energy from the sun. Springer, Dordrecht, pp 63-66

de Groot A, Lous EJ, Hoff AJ (1985) Magnetic interactions between the triplet state of the primary donor and the prereduced ubiquinone acceptor in reaction centers of the photosynthetic bacterium Rhodopseudomonas sphaeroides 2.4.1. Biochim Biophys Acta 808:13-20. doi:10.1016/0005-2728(85)90022-2

de Kanter FJJ, den Hollander JA, Huizer AH et al (1977) Biradical CIDNP and the dynamics of polymethylene chains. Mol Phys 34:857-874. doi:10.1080/00268977700102161

Diller A, Alia A, Roy E et al (2005) Photo-CIDNP solid-state NMR on photosystems I and II: what makes P680 special? Photosynth Res 84:303-308. doi:10.1007/s11120-005-0411-0

Diller A, Prakash S, Alia A et al (2007a) Signals in solid-state photochemically induced dynamic nuclear polarization recover faster than with the longitudinal relaxation time. J Phys Chem B 111:10606-10614. doi:10.1021/jp072428r

Diller A, Roy E, Gast P et al (2007b) ${ }^{15} \mathrm{~N}$-photo-CIDNP MAS NMR analysis of the electron donor of photosystem II. Proc Natl Acad Sci USA 104:12843-12848. doi:10.1073/pnas.0701763104

Diller A, Alia A, Gast P (2008) ${ }^{13} \mathrm{C}$ photo-CIDNP MAS NMR on the LH1-RC complex of Rhodopseudomonas acidophila. In: Allen J, Gantt E, Golbeck J, Osmond B (eds) Energy from the sun. Springer, Dordrecht, pp 93-96

Galland P, Pazur A (2005) Magnetoreception in plants. J Plant Res 118:371-389. doi:10.1007/s10265-005-0246-y

Gast P, Hoff AJ (1979) Transfer of light-induced electron-spin polarization from the intermediary acceptor to the prereduced primary acceptor in the reaction center of photosynthetic bacteria. Biochim Biophys Acta 548:520-535. doi:10.1016/ 0005-2728(79)90062-8

Gast P, de Groot A, Hoff AJ (1983) Evidence for an anisotropic magnetic interaction between the (bacteriopheophytin) intermediary acceptor and the first quinone acceptor in bacterial photosynthesis. Biochim Biophys Acta 723:52-58. doi:10.1016/ 0005-2728(83)90008-7

Goez M (1997) Photochemically induced dynamic nuclear polarization. Adv Photochem 23:63-164. doi:10.1002/9780470133545. $\operatorname{ch} 2$

Goldstein RA, Boxer SG (1987) Effects of nuclear-spin polarization on reaction dynamics in photosynthetic bacterial reaction centers. Biophys J 51:937-946. doi:10.1016/S0006-3495(87)83421-5

Haken H (2004) Synergetics. An introduction and advanced topics. Springer, Berlin

Hoff A (1984) Electron spin polarization of photosynthetic reactants. Q Rev Biophys 17:153-282

Hoff AJ, Gast P, Romijn JC (1977a) Time-resolved ESR and chemically induced dynamic electron polarisation of the primary reaction in a reaction center particle of Rhodopseudomonas sphaeroides wild type at low temperature. FEBS Lett 73:185-190. doi:10.1016/0014-5793(77)80977-0

Hoff AJ, Rademaker H, van Grondelle R et al (1977b) Magnetic-field dependence of yield of triplet-state in reaction centers of photosynthetic bacteria. Biochim Biophys Acta 460:547-554. doi:10.1016/0005-2728(77)90094-9

Hore PJ, Broadhurst RW (1993) Photo-CIDNP of Biopolymers. Prog Nucl Magn Reson Spectrosc 25:345-402. doi:10.1016/ 0079-6565(93)80002-B

Ivanov KL (2005) Net and multiplet CIDEP of the observer spin in recombination of radical-biradical pair. J Phys Chem A 109:5160-5167. doi:10.1021/jp0504524

Ivanov AI, Mikhailova VA, Feskov SV (1999) A model of spin catalysis in bacterial photosynthetic reaction centres. Appl Magn Reson 16:481-492

Jeschke G (1997) Electron-electron-nuclear three-spin mixing in spincorrelated radical pairs. J Chem Phys 106:10072-10086. doi: $10.1063 / 1.474063$

Jeschke G (1998) A new mechanism for chemically induced dynamic nuclear polarization in the solid state. J Am Chem Soc 120:4425-4429. doi:10.1021/ja973744u

Jeschke G, Matysik J (2003) A reassessment of the origin of photochemically induced dynamic nuclear polarization effects in solids. Chem Phys 294:239-255. doi:10.1016/S0301-0104(03)00278-7

Kaptein R, Oosterhoff JL (1969) Chemically induced dynamic nuclear polarization II (Relation with anomalous ESR spectra). Chem Phys Lett 4:195-197. doi:10.1016/0009-2614(69)80098-9

Kondepudi D, Prigogine I (1998) Modern thermodynamics: from heat engines to dissipative structures. Wiley, New York

Lendzian F, Huber M, Isaacson RA et al (1993) The electronic structure of the primary donor cation radical in Rhodobacter sphaeroides R-26 Endor and Triple resonance studies in single crystals of reaction centers. Biochim Biophys Acta 1183:139-160. doi:10.1016/0005-2728(93)90013-6

Matysik J, Alia A, Gast P et al (2000a) Photochemically induced nuclear spin polarization in reaction centers of photosystem II observed by C-13 solid-state NMR reveals a strongly asymmetric electronic structure of the $\mathrm{P} 680^{\circ}$ primary donor chlorophyll. Proc Natl Acad Sci USA 97:9865-9870. doi:10.1073/pnas.170138797

Matysik J, Alia A, Hollander JG et al (2000b) A set-up to study photochemically induced dynamic nuclear polarization in photosynthetic reaction centres by solid-state NMR. Indian J Biochem Biophys 37:418-423

McDermott A, Zysmilich MG, Polenova T (1998) Solid state NMR studies of photoinduced polarization in photosynthetic reaction centers: mechanism and simulations. Solid State Nucl Magn Reson 11:21-47. doi:10.1016/S0926-2040(97)00094-5

Polenova T, McDermott AE (1999) A coherent mixing mechanism explains the photoinduced nuclear polarization in photosynthetic reaction centers. J Phys Chem B 103:535-548. doi: 10.1021/jp9822642

Prakash S, Alia A, Gast P et al (2005a) Magnetic field dependence of photo-CIDNP MAS NMR on photosynthetic reaction centers of Rhodobacter sphaeroides WT. J Am Chem Soc 127:1429014298. doi:10.1021/ja054015e

Prakash S, Tong SH, Alia A (2005b) ${ }^{15} \mathrm{~N}$ photo-CIDNP MAS NMR on reaction centers of Rhodobacter sphaeroides. In: van der Est A, Bruce D et al (eds) Photosynthesis: fundamental aspects to global perspectives, proceedings of the 13th international congress on photosynthesis. Allen Press, Lawrence, pp 236-237

Prakash S, Alia A, Gast P et al (2006) Photo-CIDNP MAS NMR in intact cells of Rhodobacter sphaeroides R26: molecular and atomic resolution at nanomolar concentration. J Am Chem Soc 128:12794-12799. doi:10.1021/ja0623616

Roth HD (1996) Chemically induced dynamic nuclear polarization. In: Grant DM, Harris RK (eds) Encyclopedia of nuclear magnetic resonance. Wiley, New York

Roy E, Diller A, Alia A et al (2006) Magnetic field dependence of ${ }^{13} \mathrm{C}$ photo-CIDNP MAS NMR in plant photosystems I and II. Appl Magn Reson 31:193-204 
Roy E, Alia A, Gast P et al (2007) Photochemically induced dynamic nuclear polarisation observed in the reaction center of the green sulphur bacteria Chlorobium tepidum by ${ }^{13} \mathrm{C}$ MAS NMR. Biochim Biophys Acta 1767:610-615. doi:10.1016/j.bbabio.2006. 12.012

Roy E, Rohmer T, Gast P et al (2008) Characterization of the primary electron pair in reaction centers of Heliobacillus mobilis by ${ }^{13} \mathrm{C}$ photo-CIDNP MAS NMR. Biochemistry 47:4629-4635. doi: 10.1021/bi800030g

Schrödinger E (1944) What is life?. Cambridge University Press, Cambridge

Schulten EAM, Matysik J, Alia A et al (2002) C-13 MAS NMR and photoCIDNP reveal a pronounced asymmetry in the electronic ground state of the special pair of Rhodobacter sphaeroides reaction centers. Biochemistry 41:8708-8717. doi:10.1021/bi025608u

Tributsch H (2006) Kinetically determined solar cells. C R Chim 9:584-596

Tributsch H, Pohlmann L (1998) Electron transfer and new frontiers. Science 279:1891-1895
Ward HR, Lawler RG (1967) Nuclear magnetic resonance emission and enhanced absorption in rapid organometallic reactions. J Am Chem Soc 89:5518-5519

Werner H-J, Schulten K, Weller A (1978) Electron transfer and spin exchange contributing to the magnetic field dependence of the primary photochemical reaction of bacterial photosynthesis. Biochim Biophys Acta 502:255-268

Zysmilich MG, McDermott A (1994) Photochemically induced dynamic nuclear-polarization in the solid-state N-15 spectra of reaction centers from photosynthetic bacteria Rhodobacter sphaeroides $\mathrm{R}-26$. J Am Chem Soc 116:8362-8363

Zysmilich MG, McDermott A (1996a) Natural abundance solid-state carbon NMR studies of photosynthetic reaction centers with photoinduced polarization. Proc Natl Acad Sci USA 93:68576860

Zysmilich MG, McDermott A (1996b) Photochemically induced nuclear spin polarization in bacterial photosynthetic reaction centers: Assignments of the N-15 ssNMR spectra. J Am Chem Soc 118:5867-5873 